\title{
Babel do século XXI: do mito às mídias
}

\section{Renato Cordeiro Gomes}

\section{Resumo}

As imagens e os sentidos da cidade se modificam no tempo e no espaço, ligadas a contextos históricos e sociais. Nesse sentido, é que se tem dito que pensar a cidade na cultura contemporânea implica lê-la como parte integrante de um sistema comunicacional, associado ao avanço tecnológico que afeta a ordem da representação. Observa-se, entretanto, que, em tais representações nas mídias, nas artes e na literatura, recorre-se a mitos arcaicos a exemplo de Babel e sua Torre, que, desde a origem bíblica, referem-se aos fenômenos da comunicação e da cidade. Esse mito arcaico é suporte semântico que possibilita caracterizar fenômenos novos como a cidade moderna e suas derivas pós-modernas, com sua urbanidade mecânica, a atomização, o progresso, as tecnologias. Essa premissa é ponto de partida para analisar a Babel do século XXI, cenarizada e dramatizada em produtos midiáticos, que a reeditam, desde representações da destruição das Twin Towers, da babélica Nova York, até a São Paulo Fashion Week, de 2008, passando pelo filme Babel (2006), produção americana dirigida pelo mexicano González Iñárritu. Imagem da disjunção, do caos e da incomunicação, a saga de Babel aí encenada permite pôr em questão a crise da representação e dimensionar o choque de culturas, 0 drama multicultural, as barreiras territoriais, sociais, políticas e culturais da era da globalização.

\section{Palavras-chave}

0 mito bíblico de Babel. Século XXI. Globalização. Nova York. Babel, filme de González Iñárritu. Crise da representação.

\section{Renato Cordeiro Gomes | rcgomes@domain.com.br}

Doutor em Letras pela Pontifícia Universidade Católica do Rio de Janeiro - PUC-Rio. Professor do Departamento de Comunicação Social da PUC-Rio.
Já é, certamente, lugar-comum dizer que as imagens e os sentidos da cidade, toda e qualquer, modificam-se no tempo e no espaço, ligadas a contextos históricos e sociais. Nesse sentido, é que se tem dito que pensar a cidade na cultura contemporânea implica lê-la como parte integrante de um sistema comunicacional (PRYSTHON, 2006; MARTÍN-BARBERO, 2004; RESENDE, 2005), o que significa ir além das materialidades, e considerar as representações que se fazem da cidade. Já se disse, há muito, que as cidades são construídas com pedra e carne, mas também com os signos e as linguagens, de modo que as representações passem a ser integrante de um sistema comunicacional (Prysthon, 2006, p.7).

Nessa perspectiva, é que, ao discorrer sobre a vida privada no Brasil, o historiador Nicolau Sevcenko (1998) explora o fluxo de transformações causado pelos novos recursos técnicos que levam a reorientar a percepção humana. Desdobra essa observação geral para apreender o impacto das então novas tecnologias que condicionaram o desenvolvimento da cultura midiática, bem como afetaram as expectativas da sociedade e os projetos de cada indivíduo. Sobre isso, declara: 
As novas tecnologias, conquanto envolvam procedimentos e recursos que são postos e operados no espaço público, mas agenciam os desejos e as disposições psíquicas mais íntimas de cada um, influenciando a esfera mais estreita de suas deliberações em âmbito privado e interagindo decisivamente com esta. (p. 520-521).

Esse fenômeno se liga estreitamente à metropolização: 0 modo pelo qual a experiência de viver nas grandes cidades modernas, planejadas em função dos novos fluxos energéticos e marcadas pela onipresença das novas tecnologias, influencia e altera drasticamente a sensibilidade e os estados de disposição dos seus habitantes - assegura esse pesquisador da vida urbana, ao sublinhar as relações entre as novas técnicas, 0 cinema e as grandes cidades. E cita o historiador da cultura James Donald: "A metrópole moderna e a instituição do cinema surgem praticamente no mesmo momento. Sua justaposição fornece várias chaves sobre a estética pragmática pela qual experimentamos a cidade não apenas como cultura visual, mas acima de tudo como um espaço psíquico" (apud SEVCENKO, 1998, p. 522).

Tais características se agudizam ao correr do século XX e avançam pelo início do XXI. Aí, como afirma Martín-Barbero (2004), a cidade (ele destaca as sociedades latino-americanas que acumulam diversas temporalidades) é caracterizada por uma "heterogeneidade simbólica" e por uma inabarcabilidade, cuja expressão mais concreta se encontra nas mudanças nas formas de experimentar o território e viver a identidade. Para esse pensador, tais mudanças "se acham, se não determinadas, ao menos fortemente associadas às transformações tecnoperceptivas da comunicação, ao movimento de desterritorialização e internacionalização dos mundos simbólicos e ao deslocamento de fronteiras entre tradições e modernidade, entre o local e o global, entre cultura letrada e cultura audiovisual" (p. 279). Traça com essas assertivas o horizonte contemporâneo em que os processos acelerados de modernização urbana se juntam aos cenários de comunicação que "em seus fluxos e fragmentações, conexões e redes, constroem a cidade virtual" (idem), que convive com a cidade tal qual gerada pela modernidade, a partir da Revolução Industrial e o que possibilitou os avanços tecnológicos.

Esse estado de coisas afeta os regimes de representação da própria cidade, que aciona um significativo arsenal de imagens, símbolos, mitos, metáforas, narrativas, formando um repertório pronto a ser realocado, repetido, na tentativa de construir sentidos para a realidade urbana, enquanto fenômeno moderno e pósmoderno. Desse modo, tal repertório constitui uma tradição. E de tal modo que, ao olharmos as imagens da cidade nas artes, na cultura das mídias e nas ciências sociais dos últimos dois séculos, reconhecemos que nossa visão é impregnada por essas imagens que foram inscrevendo-se nessa tradição (em continuidade e transmissibilidade): a representação do objeto 
cidade é ela própria formatada pelas ações e imaginações dos sujeitos que o percebem, mesmo com concepções distintas de cidade. Quanto mais vemos a cidade moderna em sua "permanente transitoriedade", para usar a expressão de Karl Schorske (1987), mais a olhamos através de uma série de lentes (mediações).

A recorrência a determinadas imagens pode significar alguma coisa para além de uma mera referência cultural para representar a cidade, toda e qualquer. Uma dessas recorrências é facilmente verificável em seus múltiplos aspectos presentes nos mais diversos discursos das mídias e das artes. Refiro-me, aqui, à imagem de Babel e sua Torre e suas reedições no século XXI, cenarizada e dramatizada em produtos midiáticos, desde representações da destruição das Twin Towers, da babélica Nova York, até a São Paulo Fashion Week (SPFW) de 2008, passando pelo filme Babel (2006), produção americana dirigida pelo mexicano González Iñárritu.

"Babel do século XXI" é o tema da São Paulo Fashion Week, realizada em janeiro de 2008. A própria cenografia do evento é mais uma vez concebida pela dupla Daniela Thomas e Felipe Tassara, que criaram uma "torre de Babel" no vão livre do prédio da Bienal formada, com 0 aproveitamento das rampas, por andaimes e com aparelhos de TV e computadores para 0 público da SPFW.

0 tema, que direcionou a cenografia, certamente tem a ver com a moda mundializada de uma economia globalizada, que tenta minimizar as tensões com o local. Uma questão de mercado, enfim ("Só se falou de negócios no $1^{\circ}$. Dia da Fashion Week" é manchete do caderno Cidades, p. C8, do Estado de S. Paulo, de 17/01/2008). Além da moda como negócio, a SPFW pode ser índice de outros fenômenos mais do âmbito cultural, a exemplo da convivência de tendências das mais variadas de estilos, materiais, cores. Pode também apontar para um fenômeno temporal: a fixação de um instante, um presente efêmero que, por sua vez, recicla um passado (a tradição) com que a moda de hoje tenta dialogar, na busca da contemporaneidade estreitamente ligada ao up-to-date da internacionalização das tendências fashion, na tentativa de superar os traços nacionais: a moda firma-se enquanto cosmopolita, urbi et orbi, como o caderno "Ela", de $O$ Globo (19/01/2008, p.4), se referiu ao Fashion Rio, realizado pouco antes da semana paulista. Parece que o Rio e São Paulo servem apenas como nomes da localização do evento: a Babel fashion é aqui, ou em qualquer lugar. A moda cosmopolita, por razões econômicas e culturais, é, por isso mesmo, babélica, mas tenta ordenar o caos, a desorientação de sentido, a confusão, que caracteriza o mito arcaico, que teima em ser incessantemente atualizado, desde sempre. A ênfase desse mito ocorre desde 0 início da modernidade, quando Babel metaforizou a cidade transformada pela Revolução Industrial e ocupada pela multidão, e a moda ganhou sua feição moderna para atender aos novos 
consumidores. Desde aí moda e consumo deramse os braços e foram ganhando os templos das mercadorias, desde as galerias de vidro e ferro (BENJAMIN, 2006), os grandes magazins, as lojas de departamento, até os shopping-centers pós-modernos: são versões sucessivas de um mundo babélico e labiríntico, sem dúvida, unindo 0 recente contemporâneo (de cada momento histórico) e os resíduos do mito arcaico, evocado para nomear o que se quer sempre novo, essa categoria moderna, de que nem o pós-moderno consegue se desvencilhar.

Estranha combinação que une um mito bíblico com a realidade urbana moderna, fadada a ver sua reedição ganhar intensidade ao correr dos séculos XIX e XX: a mesma estranheza já sem a marca do choque moderno e modernista que se pode ver no tema do SPFW - outono-inverno 2008. A Babel da mistura, já ordenada pelo mercado ("Ninguém quer saber de coleção, todo mundo só pergunta de negócios", declara ao Estadão o estilista Alexandre Herchcovitch), acaba unindo 0 arcaico e 0 atualíssimo praticamente sem tensão, nesse presente midiático, que deixa de ser signo do futuro, quem sabe realizando a "Babel feliz", para se aproveitar a formulação de Roland Barthes (1974, p.36), em contexto bem distinto (seria esta Babel a do consumo e do mundo efêmero da moda?).

A metáfora de Barthes, entretanto, não se inscreve numa tradição que vê Babel como alegoria (ou símbolo) do desafio e da destruição, a partir do caos original do mito bíblico. 0 mito de Babel (Gen. 11, 1-9) é um acontecimento de disjunção que, em sua estrutura narrativa, é circunstanciado como fenômeno e catástrofe social. A Torre é o símbolo da confusão, e sua construção indica centramento, desafio do homem que se eleva desmesuradamente. Símbolo da empresa orgulhosa e tirânica, sua destruição aponta para o desvio, a dificuldade de comunicação (tema que as narrativas literárias e midiáticas exploram fartamente) e 0 isolamento como castigo ("Confundamos a sua linguagem para que não mais se entendam uns aos outros", diz a Bíblia); é resultado da explosão da humanidade em frações hostis.

0 mito babélico envia à crítica da urbanidade mecânica, da rapidez, do gigantismo crescente (e daí facilmente grudado às representações da cidade moderna). Ilustra a dificuldade de comunicação, o tempo e 0 espaço esfacelados, mas expressando, igualmente, um empreendimento ligado a um permanente recomeçar. Associa-se, portanto, em sua projeção na metrópole moderna, ao espetáculo disforme da cidade fragmentada, desse universo descontínuo marcado pela falta de medida. Se a dispersão babélica motivou as tentativas de fazer emergir na cidade o diálogo humano como resistência à incompreensão, se o diálogo é 0 símbolo mais pleno e a justificativa final da vida na cidade - segundo reivindica Mumford (1982, p. 134) -, o caos das metrópoles retoma quase circularmente a Babel mítica. 
0 mito bíblico se torna recorrente, enquanto suporte semântico de uma série de produtos midiáticos, que se orientam para uma nova síntese simbólica agregada a essa forma mítica arcaica, com a qual procuram formalizar uma representação da cidade em permanente atualização modernizadora, emblematizada na imagem de um edifício-torre em construção, ou de sua destruição. 0 cinema é particularmente rico nesse sentido, numa tradição que vai de Metropolis (1926), de Fritz Lang, passando por Blade Runner (1982), de Ridley Scott, a Babel (2006), de González Iñárritu, a que podemos juntar Lost in translation (2001) [Encontros e desencontros, título no Brasil], de Sophia Coppola. Essa série midiática pode ser associada a uma outra literária em que podem ser inscritos textos como "0 emblema da cidade" (1920), pequena parábola de Kafka, o conto "0 edifício" (1965), do mineiro Murilo Rubião (1974), até obras pós-modernas a exemplo da novela City of glass (Cidade de vidro) (1985), da Trilogia de Nova York, de Paul Auster, ou mesmo o romance Cosmópolis (2003), de Don DeLillo.

Tais obras podem remeter ao projeto urbanístico da modernidade e seus mecanismos de controle, ao mesmo tempo em que põem em tela a crise da representação, atrelada à "reorientação simbólica tornada possível pela disjunção entre a base religiosa de um mundo longamente estável e a irrupção desestabilizadora das novas tecnologias, assentadas sobre a aceleração, a fragmentação e a concentração isoladas das grandes cidades"
(SEVCENK0, 1992, p.171). Essas novas

tecnologias modificam radicalmente a percepção e a sensibilidade urbanas e alteram 0 imaginário e a subjetividade, na linha demonstrada por Georg Simmel (1987), no ensaio "A metrópole e a vida mental", de 1902.

A disjunção, que é marca babélica, atrelada ao desenvolvimento das tecnologias, funciona como traço recorrente desses filmes e narrativas citados, permitindo aí perceber, de modo explícito ou implícito, uma questão instigante: como representar a cidade que é Babel, no seu excesso, quando se rompem meios disponíveis para tal? A indagação implica, no mesmo diapasão, um corolário: com que linguagem representá-la, enquanto acontecimento, enquanto desastre, enquanto catástrofe, que remete à destruição? Ou dito de outra forma, como fazê-la significar; ou seja, como interpretála para atribuir-lhe sentidos, estendendo o ângulo de visão em direção à modernidade como catástrofe e choque contínuo? Tal cadeia de associações demonstra que as tentativas de representar esses fenômenos afetam a própria ordem da representação.

Exemplo cabal desse impasse que diz respeito à representação e sua impossibilidade, pode ser apreendido justamente em relação ao 11 de Setembro, a destruição das Twin Towers, esse símbolo da Babel pós-moderna, do capitalismo globalizado: as Torres que remetem ao motivo temático do arranha-céu, emblema da 
arquitetura moderna já cenarizada pelo cinema a partir de Metropolis, o filme expressionista de Fritz Lang. Refiro-me à capa da revista The New Yorker, de 24 de Setembro, intitulada "09/11/01", de Art Spiegelman. A primeira capa depois dos atentados ocupa-se com aquele impasse: como representar as Torres, frente ao excesso de realidade, ao que não pode ser nomeado, ao que é inimaginável, depois do desaparecimento desse outro símbolo ascensional, que remete a Babel, essa moldura arcaica, que sempre freqüentou o imaginário da arquitetura e do urbanismo modernos (COQUELIN, 1982, p. 49). 0 recurso puramente gráfico aplicava um preto 100\% para as silhuetas das duas torres do World Center sobreposto a um preto $90 \%$, sugerindo uma inscrição a indicar o que houvera ali, no agora ground zero, onde em seguida haveria dois focos de luz, mera sugestão, material e simbólica, de que ali, no vazio, uma era fora abalada e de que se estava começando um novo século: a incerteza aberta num presente precário e ao mesmo tempo expansivo.

Outra associação pode ser feita com a participação do cineasta mexicano Alejandro González Iñárritu do projeto 11' 09' 01, realizado em 2002 por Alain Brigad e Jacques Perrin, que buscou diferentes interpretações sobre os atentados de Nova York, reunindo 11 filmes, condicionados simbolicamente peloframe de duração expresso pelo título do projeto. 0 diretor mexicano utilizou imagens precárias de baixa qualidade, nas quais somente se distinguiam por pequenos flashes iluminando imagens de pessoas caindo, ou pulando, das torres e o momento do desmoronamento dos edifícios. Tais imagens contrastam com a tela negra, sem luz, a ausência de imagem, que indica a impossibilidade de uma representação numa narrativa linear e causal. Recoloca-se a questão: como representar 0 irrepresentável? A tentativa recai sobre aquele recurso luz/ausência de luz, imagem/ausência de imagem, coadjuvado por uma espécie de trilha sonora (antes um bruitage), em que se usou áudio de transmissões de rádio e TV, também confusas, mixando fragmentos provenientes de vários países, em línguas diversas, com a reutilização de materiais do jornalismo, mas conferindo-lhes um tratamento que aponta para a incomunicabilidade, como numa Babel de sons e imagens: Babel = a desorientação do sentido. 0 caos, a destruição dos sentidos, era expresso através do próprio material que compõe uma moldura temporal, preenchida com as imagens deslocadas e o ruído indecifrável das palavras. A disjunção e a fragmentação foram incorporadas à própria estruturação e à própria estética do filme. A única frase de fato compreensível nesse curta, parte de um todo maior, aparecia escrita na tela: "Does God's light guide us or blind us?" (HENRIQUES, 2005, p. 43-68).

Tanto na capa do periódico novaiorquino quanto no filme de Iñárritu, a impossibilidade da representação e de sentido é colocada em pauta porque há uma comunidade de imaginação, que permite a utilização de símbolos como elementos 
de legitimação de uma idéia, ao mesmo tempo em que 0 autor e 0 leitor compartilham determinada carga emotiva que os afeta e permite circular possíveis sentidos por essa comunidade que é também discursiva.

0 projeto 11'09' 01, de que o filme de Iñárritu faz parte, juntou-se a uma série de outros discursos midiáticos ou mesmo ensaísticos, gerando, de certa forma, uma arena discursiva, conotando embate de práticas, valores (políticos, éticos, religiosos, estéticos), tensões de vozes e concepções de mundo, provocando o surgimento de novos lugares de enunciação e possibilitando o jogo agônico de discursos e contradiscursos: há de fato a encenação (o espetáculo) de uma guerra de relatos. Fica a pergunta: como narrar/ representar aquele tempo presente, aquele acontecimento, aquela catástrofe? Há uma precariedade dos instrumentos para lidar com aquele presente centrado na imagem e nos sentidos de Babel (remetendo ao mito arcaico e sempre atualizado) e que dele se dissemina, mais ou menos, sem controle. Há um presente expandido, em seu excesso, simbolicamente representado pelos escombros, pela poeira semelhante ao que analisa Raúl Antelo no texto "Maximam, et nullam" (2005, p. 189-190) em relação ao Terremoto de Lisboa de 1755 - ; há um espaço de embate entre ordem e desordem, um espaço de sentido a ser construído, embora haja qualquer coisa que escape. Daí o colocar-se em questão a representação, redundantemente dita no problema: como representar o irrepresentável.
Aponta-se para 0 inefável, para os limites da linguagem: a relação de muitos textos com 0 evento a que se refere, é de ordem indicial, mais do que representativa.

A imagem orgulhosa das torres gêmeas do World Trade Center indicava a afirmação de valores modernos do progresso, bem como a supremacia da economia capitalista globalizada, sob a hegemonia dos Estados Unidos. Os atentados daquela terça-feira reforçaram 0 significado mundial da idéia de cidade. Os acontecimentos do 11 de setembro visaram o símbolo central de um certo conceito de civilização: a idéia e a imagem da cidade (COELHO, 2002, p. 45), emblematicamente representada pela torre, que em sua verticalidade ascensional, conotando desafio e poder, é tópico indisfarçável na história da cidade, da cultura e da arte, que recorre a uma forma arcaica (Babel, reafirmamos), obsessão no imaginário urbano. A forma duplicada das Torres, entretanto, significava um ponto final na verticalidade, como ressalta Baudrillard (2003, p. 12), contrastando com o conhecido panorama arquitetônico da cidade. "0 fato de que eram duas significa a perda da referência original. Se houvesse apenas uma, o monopólio [sem concorrência] não estaria perfeitamente encarnado. Somente a duplicação do signo acaba realmente com 0 que ele designa [...] Culminam no exato reflexo uma da outra" - acrescenta 0 pensador francês, ao ver nas Torres Gêmeas a imagem do sistema (2003, p. 12). A fragmentação concreta, via destruição pela ação terrorista, 
representa também a fragmentação simbólica desse sistema, e, portanto, de identidades e valores, que a ficção midiática e a literária já vinham explorando havia algum tempo. "Ao atacálas, os terroristas atingiram o centro nevrálgico do sistema. A violência do global também passa pela arquitetura, pelo horror de viver e de trabalhar nesses sarcófagos de vidro, aço e concreto. 0 pavor de morrer é aí inseparável do pavor de aí viver. Por isso a contestação dessa violência passa também pela destruição dessa arquitetura" (BAUDRILLARD, 2003, p. 13).

As imagens da destruição das torres repetidas fartamente por todos os meios massivos foram, numa primeira impressão, tomadas como imagens ficcionais: "parecia um filme" - dizia a voz corrente dos telespectadores, que, de pronto, duvidavam do que viam. Imediatamente, as imagens do 11 de setembro foram associadas a filmes como Nova York sitiada (1998), escrito por Larry Wright e dirigido por Edward Zwick: "Algumas cenas do filme que conta a história de uma cidade vítima de inimagináveis atentados terroristas, foram literalmente reproduzidas na última terça-feira, quando dois Boeing-767 foram lançados contra a símbolo máximo do capitalismo americano, o World Trade Center", registra a jornalista Milly Lacombe, na Ilustrada da Folha de S. Paulo, de 14 de setembro de 2001, quando entrevista o roteirista do filme. Depõe Larry Wright: "Assisti à TV em estado de choque. [...] Quando escrevi Nova York sitiada tive 0 cuidado de não extrapolar muito minha alucinações. Mas, pelo visto, minha imaginação ficou aquém da capacidade desses lunáticos". Via ele pela TV, naquela manhã, que sua obra de ficção, que lidava com imagens e circunstâncias exageradamente dramáticas e assustadoras, tinha virado realidade da forma mais dramática e surreal possível: " 0 cenário foi mais apavorante do que o que, sem querer, antecipei", completa.

Tem-se afirmado que depois dos atentados de 11 de setembro, Nova York foi, de certa forma, obrigada a repensar a sua identidade já múltipla, heterogênea e fragmentada, como qualquer megalópole contemporânea, associada a Babel. A destruição do símbolo duplicado pôs a nu a fragilidade da potência mundial. "Ao mesmo tempo objeto arquitetônico e objeto simbólico, evidentemente que se visou o objeto simbólico; pode-se imaginar que a destruição física acarretou o desabamento simbólico. Mas é 0 contrário: a agressão simbólica acarretou 0 desabamento físico" (BAUDRILLARD, 2003, p. 14). Por outro lado, não se pode ignorar o que afetou a população da cidade em seu cotidiano. Ao buscar compreender 0 fato, o habitante da cidade tomou consciência de que ela ficou destrutível. Não é, entretanto, a primeira vez que essa vulnerabilidade é constatada. A paisagem e as cenas que vimos das torres arruinadas não puderam deixar de lembrar as sequiências mais impressionantes dos grandes filmes de catástrofe, a exemplo de Daylight (1996), de Rob Cohen, como lembra a filósofo esloveno Slavoj Zizek (Mais!, Folha de S. Paulo, de 23 set. 2001). 
Aquela antecipação de que fala 0 roteirista de

Nova York sitiada pode ser lida no ensaio de E.B. White (1899-1985), Aqui está Nova York, editado em 1949, na revista The New Yorker, que registra premonitoriamente essa possibilidade, quando a "suspeita da mortalidade" passa fazer parte da cidade que ele associa a uma "ilha da fantasia". Ressalta, então:

A cidade, pela primeira vez em sua história, ficou destrutível. Uma simples revoada de aviões pode rapidamente acabar com a ilha da fantasia, queimar as torres, desmoronar as pontes, transformar as galerias do metrô em câmaras letais, cremar milhões. A suspeita da mortalidade faz parte agora de Nova York: no som dos jatos sobre nossas cabeças, nas manchetes pretas da última edição. (WHITE, 2002, p. 52-53).

A recorrentíssima associação de Nova York com Babel pode ser vista como um recurso retórico, funciona, por sua vez, como condicionador de legibilidade. Um fenômeno novo (surpreendente, impensável) requer molduras antigas para ser representado, semelhante ao que Walter Benjamin apontou, ao falar nas representações das cidades modernas (BENJAMIN, 1989, p. 226). Daí, a recorrência de expedientes discursivos que lançam mão desses suportes arcaicos presentes no imaginário em que circulam essas imagens com significado já dado por discursos anteriores (uma tradição), que serão manipulados ideologicamente e a que se agregam elementos do presente expansivo, que se quer interpretar. Parece que há mesmo uma busca de direção nesses movimentos dispersos e destituídos de rumo (= sentido) bem delineado; em meio à dispersão, há uma demanda de direção cumulativa, semelhante ao que Zygmunt Bauman viu nas vanguardas (1998, p. 122). Assim, do terreno físico ao mítico-símbólico, os discursos que buscam representar apontam para os modos pelos quais os homens dele se apropriam como fenômeno cultural e, por isso, como construção de paradigmas de interpretação e existência simbólica

As conseqüências do 11 de setembro - vemos hoje - foram mais duradouras para a própria noção de catástrofe (SELIGMAN-SILVA, 2000, p. 73-97), que se materializa no próprio real, no cotidiano do século XXI. É nessa clave que a modernidade pode ser lida como cultura da catástrofe e do choque contínuo, que esteticamente vai requerer novos gêneros para representar a experiência do homem moderno, que requer novas respostas artísticas (SCHOLLHAMMER, 2005, p. 57).

Se a catástrofe desse símbolo babélico foi também lida/representada como espetáculo, no sentido que damos hoje ao termo (DEBORD, 1971), foi também visto, ironicamente, como a festa pública (spetaculum), associando um sentido oculto, profundo, um fundamento, com espaço público, oferecendo-o ao espectador, aquele que, colocando-se em um determinado lugar, vê o espetáculo e é capaz de voltar-se para o speculandus - com a acepção de especular, investigar, examinar, vigiar, observar -, operações que se associam à ordem da representação. 
Nesse especular, o discurso que especula, nem sempre funciona como espelho, que representa o que é oferecido do espetáculo, mas é capaz de pôr em questão a própria representação, examinando os mecanismos da linguagem e os modos do discurso que fundamentam suas possibilidades e seus impasses. Enfim, está em jogo a própria ordem do discurso, com suas implicações ideológicas, políticas, religiosas, éticas e estéticas, como os discursos que se produziram sobre as Twin Towers, em seu excesso, podem atestar.

Especular ainda hoje sobre Babel é o que faz Iñárritu em sua produção de 2006, na busca de respostas artísticas que a mídia cinematográfica permite equacionar para 0 violento mundo deste século XXI, efetivamente inaugurado pela catástrofe do World Trade Center. É o que 0 cineasta mexicano, com roteiro dele e de outro mexicano, o escritor Guillermo Arriega [os dois se desentenderam justamente por causa da autoria de Babel, depois de uma parceria nos filmes anteriores: Amores brutos (Amores perros, 2001) e 21 gramas (2003)] - fez em seu longa metragem sintomaticamente intitulado Babel, produção americana de 2006. Pode-se até levantar como hipótese que está respondendo à pergunta de Canclini, expandindo-a para além da cidade do México: "0 que ocorre quando não se entende o que uma cidade está dizendo, quando esta se converte numa Babel, e a polifonia caótica de suas vozes, seu espaço desmembrado e as experiências disseminadas de seus habitantes diluem o sentido dos discursos globais?" (2006, p. 78).

Pode-se mesmo dizer que a película de 2006 seria uma "Babel do século XXI", com conotações bem distintas da São Paulo Fashion Week, enquanto drama do mundo contemporâneo. No filme, os conflitos não são neutralizados, mas, pelo contrário, potencializados, num mundo que se tornou uma imensa Babel, em que tudo se conecta, instantâneo. Filme sobre a globalização, choque de culturas, drama multicultural, histórias simultâneas, olhar diferente às barreiras culturais e de linguagem na era da globalização e dificuldades de comunicação foram algumas das expressões dos comentários que circulam pela Internet, ligadas de modo explícito ou implícito ao emblemático título, a menor síntese dos sentidos do filme, atualizando em diferença sentidos herdados de uma longa tradição que remete ao mito bíblico. 0 título ao mesmo tempo funciona enquanto marca de um produto simbólico e midiático, que ganha legitimidade pela assinatura do diretor (a produção anterior participa dessa instância de autorização) e pelos prêmios que arrebatou pelo mundo, do Oscar ao Globo de Ouro até o Festival de Cannes, além de muitas indicações a diversas categorias.

Com locações em Ibaragi, Shinjuku e Tóquio, no Japão; El Carrizo e Sonora, no México; Tijuana, na Baja Califórnia, também no México; Ouarzazate e Taguenzalt, no Marrocos, em 
uma vila bérbere aos pés dos Montes Atlas e construída nas encostas rochosas do vale do Rio Draa; e San Diego, na Califórnia, nos EUA, a saga de Babel é filmada em cinco línguas, e daí ser sempre legendado, construindo uma intensa dimensão dramática no uso de liguagens diferentes: 0 caos babélico da dificuldade de comunicação, da necessidade de tradução, aliás sempre precária, insuficiente, a que se juntam outras instâncias da linguagem tais como a violência e sua retórica, os afetos (o choro de vários personagens como a babá mexicana, ou a adolescente japonesa, liga os mundos na narrativa fragmentada e simultânea do filme), a linguagem dos sinais, a das anotações, a retórica da política internacional, o hibridismo da linguagem da fronteira. Instâncias que passam a índices da linguagem na era da globalização, dimensionada dramaticamente em referência às barreiras culturais, a exigir tradução cultural, abrindo espaço de contestação discursiva que se encaminha para um relativismo histórico e cultural em que as tensões entre barbárie e civilização perdem seus valores etnocêntricos (BHABHA, 1998, p. 310-315). Os conflitos que movem a narrativa de Babel são marcados, assim, pela incomunicação, pela intolerância, pela violência, pela disjunção (essa característica já inscrita no mito bíblico), que se ligam a questões do século XXI - tais como os deslocamentos, pelas diásporas e pelo turismo - 0 atravessamento das fronteiras territoriais e simbólicas, ao mesmo tempo que são respostas (é típica nesse sentido a história da babá mexicana de volta ao seu país com as duas crianças americanas). Se esses conflitos são abordados em dimensão social e política como González Iñárritu declarou em várias entrevistas, trazem a marca cultural, que, na perspectiva babélica do mundo atual, exige tanto na instância diegética quanto na recepção dos espectadores uma tradução cultural, semelhante ao que Walter Benjamin descreve como a "estrangeiridade das línguas" - aquele problema de representação inato à própria representação, como adverte Bhabha (1998, p. 311-312). A problemática da tradução é mesmo uma das questões articuladas no filme, como também será no babélico filme Lost in translation, de Sophia Coppola. (a respeito da tradução como impasse derivado de Babel, ver DERRIDA, 1998).

Ao articular na própria narrativa diferentes espaços e tempos em simultaneidade, essa obsessão das vanguardas, 0 filme de Iñarritu perde a dimensão do futuro para atrelar-se ao presente: a narrativa está presa ao agora em que tudo está, ao mesmo tempo conectado e disjuntivo. 0 que permite a encenação da diferença cultural, que os personagens não entendem em sua totalidade, impedindo a troca inerente à comunicação que se dá em ato, performaticamente. Cabe aqui a formulação de Bhabha (1998) que autoriza dizer-se que os personagens de Babel vivem em numa espécie de exílio: "A tradução é a natureza performativa da comunicação cultural. É antes a linguagem 
in actu (enunciação, posicionalidade). E o signo da tradução conta, ou "canta", continuamente os diferentes tempos e espaços entre a autoridade cultural e suas políticas performativas" (p. 313).

São justamente as instâncias espaciais (detaquese a imensa relevância da dimensão territorial da película) e temporais (destaque-se aqui a simultaneidade), que constroem o caos babélico da narrativa. Iñárritu, ao trabalhar 0 acaso (HENRIQUES, 2005), acredita, na linha da teoria do caos, que um acontecimento, por mais prosaico e banal que pareça, sempre integra uma cadeia de causas e conseqüências que se desdobra de maneiras imprevisíveis em dramas de natureza trágica. Tal tomada de posição indica um modo de narrar, um gesto discursivo e imagético da enunciação para adequar-se à confusão babélica, dramatizada em cinco dias e em quatro núcleos, dois no Marrocos, outro na fronteira México/EUA e outro no Japão.

Numa síntese bastante redutora da complexidade narrativa, poderíamos dizer com Rodrigo Carreiro [documento eletrônico]:

No país africano, acompanhamos dois garotos pastores de cabras e um casal de turistas americanos. 0s meninos, brincando com o rifle que usam para afastar os chacais dos caprinos, atingem sem querer 0 ônibus onde viajam Richard (Pitt) e Susan (Cate Blanchett). Enquanto isso, nos Estados Unidos, os filhos do casal estão sob os cuidados de Amelia (Adriana Barraza), a babá chicana que precisa dar um jeito de ir ao casamento do filho, do outro lado da fronteira. Em paralelo, "Babel" também enfoca a vida, no Japão, de uma garota surda-muda (Rinko Kikuchi), sofrendo com a solidão a que a adolescência condena as pessoas, algo agravado pela condição médica e por uma tragédia do passado.

Num primeiro momento, o filme não esclarece qual a ligação entre a história japonesa e os dramas que se desenrolam em dois desertos, o marroquino e o californiano, mas obviamente existe uma conexão, revelada na segunda metade da trama.

0 acaso de um tiro de rifle que atinge a turista americana leva a conexões com as outras histórias paralelas, tendo justamente a arma (cuja origem está no Japão) como leit-motiv. E todas caminham para a tragédia graças à incapacidade de comunicação, seja política, ou a verbal, ou mesmo a relacionada à deficiência. Na verdade, o filme é sobre aquilo que divide homens, mulheres, nações, países, pais e filhos, no mundo do século XXI, essa Babel globalizada, não uma Babel feliz. Ainda a Babel da desmedida, ainda caos, confusão, desorientação dos sentidos, atomização da comunicação, traços já inscritos no mito bíblico, essa persistente saga do imaginário ocidental. Essa narrativa que Kafka (1987) numa pequena parábola, "0 emblema da cidade", escrita em 1920, reinterpreta, reatualizando-a para a modernidade tomada pela obsessão do progresso, para expor um exercício premonitório, que o filme de González Iñárritu complexifica e que Don DeLillo dramatiza, em Cosmópolis (2003), mistura caótica de todas as culturas, todas as etnias, todas as línguas, num dia da Nova York comandada pela tecnologia das redes comunicacionais. 
"0 emblema da cidade", ao retomar o mito da torre de Babel dramatiza um projeto de construção que, pautado por um sistema racionalizado para a produção de signos e de imagens, estabelece hierarquias e conflitos. A torre e a cidade como um fazer sem fim, sempre incompleto, são produtos da racionalidade geradora e atrelam-se ao totalitarismo dos planejadores, burocratas e elites corporativas que traçam as normas de controle. A verticalidade da torre expressa 0 reconhecimento do sem-sentido da construção, marcada com 0 símbolo da intensidade vertical da cidade como celebração da tecnologia automatizada em relação ao humano (GOMES, 1994, p.76-89).

A celebração da tecnologia em seu paroxismo é satirizada pela narrativa de DeLillo, que relata um certo dia de abril de 2000, na vida do multimilionário Eric Michael Packer, 28 anos, dono da Packer Capital, que, preso pelo engarrafamento, é obrigado a passar o dia inteiro dentro de uma limousine, de onde controla os negócios, recebe assessores e tem encontros amorosos. No decorrer do dia, a existência de Eric é gradualmente corroída: suas certezas e valores se revelam vazios, ao mesmo tempo em que 0 sistema financeiro global é arrastado para uma crise sem precedentes.

A narrativa em forma de fábula sobre uma cosmópolis desumanizada, fruto das tecnologias e do sistema do capitalismo globalizado, atesta as preocupações do autor com as formas de controle que a sociedade moderna impôs aos indivíduos. A cosmópolis, aqui representada por Nova York, literalmente nomeada como Babel, é um submundo urbano, em que as implicações com a tecnocracia, com o capitalismo globalizado e as modificações das relações humanas, vão compor o quadro submetido à paródia e à sátira, para reivindicar, através da própria trama e das reflexões que se tecem nessa trama, a preservação dos valores humanos fundamentais. Esse cosmopolitismo de um centro hegemônico está atrelado ao "imperativo digital" (a imagem é de DeLillo), à tecnologia, que, na Babel que é o século XXI, gera novos modos de simbolização e ritualização dos laços sociais que se tecem pela mediação das redes comunicacionais, do "imperativo digital", da cibercultura. Babel midática.

\section{Referências bibliográficas}

ANTEL0, R. Maximam, et nullam. In: BUESCU, H. e CORDEIRO, G (coord.). 0 grande terramoto de Lisboa: ficar diferente. Lisboa: Gradiva, 2005. p. 189-190.

BARTHES, Roland. 0 prazer do texto. Tradução: Maria Margarida Barahona. Lisboa: Edições 70, 1974.

BAUDRILLARD, J. Power inferno. Tradução: Juremir Machado. Porto Alegre: Sulina, 2003.

BAUMAN, Z. 0 mal-estar da pós-modernidade. Rio de Janeiro: Jorge Zahar, 1998.

BENJAMIN, W. Charles Baudelaire, um lírico no auge do capitalismo. São Paulo: Brasiliense, 1989.

- Passagens. Organização: BOLLE, Willi; MATTOS, Olgária.Tradução: Irene Aron, Cleonice Paes Barreto Mourão, Patricia de Freitas Camargo. Belo Horizonte: Ed. UFMG, 2006. 
BHABHA, H. 0 local da cultura. Belo Horizonte: Ed, UFMG, 1998.

\section{CANCLINI, N. G. Consumidores e cidadãos:} conflitos multiculturais da globalização. Rio de Janeiro: UFRJ, 2006.

CARREIRO, R. Babel. Disponível em < http:// www.cinereporter.com.br/scripts/monta_noticia. asp?nid=1673> Acesso em: 27 dez. 2007.

COELHO, T. Arte na metrópole. Bravo!, São Paulo, ano 5, n. 54, p. 45-48, mar. 2002.

COQUELIN, A. Essais de philosophie urbaine. Paris: PUF, 1982.

CORPS ÉCRIT, n. 36: Babel ou la diversité des

langues. Paris: Presses Universitaires de France, 1991.

DEBORD, G. La societé du spectacle. Paris: Champ Libre, 1971.

DELILLO, D. Cosmópolis. Tradução: Paulo Henriques Brito. São Paulo: Companhia das Letras, 2003.

DERRIDA, J. Torres de Babel. Belo Horizonte: UFMG, 1998.

GOMES, R. C. Todas as cidades, a cidade. Rio de Janeiro: Rocco, 1994.

HENRIQUES, A. de S. A perda de um tempo: a obra de Alejandro González Iñárritu. In: Tempos de acaso: a temporalidade descontínua e a tematização do acaso no cinema contemporâneo. 2005. Dissertação (Mestrado em Comunicação)- Pontifícia Universidade Católica, Rio de Janeiro, 2005. p. 43-68.

KAFKA, F. 0 emblema da cidade. In:

Parábolas e fragmentos e Cartas a Milena.

Tradução: Geir Campos. Rio de Janeiro: Ediouro, 1987.

MARTÍN-BARBERO, J. Ofício do cartógrafo:

travessias latino-americanas da comunicação na cultura. São Paulo: Loyola, 2004.
MUMFORD, Lewis. A cidade na história. São Paulo: Martins Fontes, 1982.

PRYSTHON, A. Imagens da cidade: Espaços urbanos na comunicação e cultura contemporâneos. Porto Alegre: Sulina, 2006.

RESENDE, F. Cidade, comunicação e cultura: a diferença como questão. Logos, Rio de Janeiro, v.1, n.22, p. 118-136, 2005.

SCHOLLHAMMER, K. E. As imagens do desastre. In: OLINTO, Heidrum Krieger; - (orgs.).

Literatura e imagem. Rio de Janeiro: Galo Branco, 2005, p. 53-60.

SCHORSKE, C. E. La idea de cuidad em el pensamiento europeo de Volataire a Spengler. Punto de Vista, Buenos Aires, n. 30, jul.-ago. 1987.

SELIGMAN-SILVA, M. 2000. A história como trauma. In: NESTROVSKI, A.; . Catástrofe e representação. São Paulo: Escuta, 2000, p. 73-97.

SEVCENKO, N. A capital irradiante: técnica, ritmos e ritos do Rio. In: SEVCENKO, N. (org.). História da vida privada no Brasil. Vol. 3: República: da Belle Époque à era do rádio. São Paulo: Companhia das letras, 1998.

0 futuro da cidade tal como visto por Kafka do alto da Torre de Babel. Correio Braziliense, Brasília, 2 set. 1994.

Orfeu extático na metrópole: São Paulo, sociedade e cultura nos frementes anos 20. São Paulo: Companhia das Letras, 1992.

SIMMEL, G. A metrópole e a vida mental. In: VELHO, 0. (org.). 0 fenômeno urbano. Rio de Janeiro: Guanaraba, 1987.

WHITE, E. B. Aqui está Nova York. Tradução: Ruy Castro. Rio de Janeiro: José Olympio, 2002.

ZIZEK, S. Mais!, Folha de S. Paulo, 23 set. 2001 


\section{$21^{\text {st }}$ century's Babel: from the myth to the media}

\section{Abstract}

The images and the senses of the city change in time and space due to historical and social contexts. It is in this sense that it has been said that thinking the city in the contemporary culture implies reading it as a component of a communication system, associated to the technological advance that affects the order of representation. It is observed, however, that, in such representations in the media, in the arts and in the literature, one appeals to archaic myths, such as Babel and its tower, that, since its biblical origin, refers to the phenomena of communication and the city. This archaic myth is the semantic support that makes possible to characterize new phenomena such as the modern city and its postmodern derivatives, with its mechanical urbanity, atomization, progress, and technologies. This assumption is the starting point to analyze the Babel of the 21st century, scenerized and dramatized on media products, that reedit, from the representations of the Twin Tower's destruction of the babelic New York City, to the São Paulo Fashion Week 2008, passing through the movie Babel (2006), an American production directed by the Mexican González Iñárritu. Image of disjunction, chaos, and uncommunication, Babel's saga in such stage allows one to put in question the crisis of the representation and to measure the shock of cultures, the multicultural drama, the social, political and cultural barriers of the globalization age.

\section{Keywords}

The Babel's biblical myth. 21st century. Globalization. New York. Babel, González Iñárritu's film. Crisis representation.

\section{Babel del siglo XXI: del mito a los media}

\section{Resumen}

Las imágenes y los sentidos de la ciudad se modifican en el tiempo y en el espacio, ligados a contextos históricos y sociales. En esa media, es que se dice que pensar la ciudad en la cultura contemporánea implica leerla como parte integrada a un sistema comunicacional, asociado al avance tecnológico que afecta el orden de la representación. Se observa, sin embargo, que en tales representaciones en los medios, en las artes y en la literatura, se recurre a mitos arcaicos, un ejemplo es de Babel y su torre, que, desde el origen bíblico, se refiere a los fenómenos de comunicación y de la ciudad. Este mito arcaico es soporte semántico que posibilita caracterizar fenómenos nuevos como la ciudad moderna y sus derivados pos-modernos, con su urbanidad mecánica, la atomización, el progreso, las tecnologías. Esta premisa es punto de partida para analizar la Babel del siglo XXI, escenificada y dramatizada en productos mediáticos, que la reeditan, desde representaciones de destrucción de las dos torres, de la babélica Nueva York, hasta el São Paulo Fashion Week, de 2008, pasando por la película Babel (2006), producción americana, dirigida por el mexicano Gonzáles Iñárritu. Imagen de la disyunción, del caos y de la incomunicación, la saga de Babel ahí representada permite poner en cuestión la crisis de la representación y dimensionar el choque de culturas, el drama multicultural, las barreras territoriales, sociales, políticas y culturales de la era de la globalización.

\section{Palabras clave}

El mito bíblico de Babel. Siglo XXI. Globalización. Nueva York. Babel, película de González Iñárritu. Crisis de la representación. 


\section{Expediente}

A revista E-Compós é a publicação científica em formato eletrônico da Associação Nacional dos Programas de Pós-Graduação em Comunicação (Compós). Lançada em 2004, tem como principal finalidade difundir a produção acadêmica de pesquisadores da área de Comunicação, inseridos em instituições do Brasil e do exterior.

\section{E-COMPÓS I www.e-compos.org.br I E-ISSN 1808-2599}

Revista da Associação Nacional dos Programas de Pós-Graduação em Comunicação. Brasília, v.11, n.1, jan./abr. 2008.

A identificação das edições, a partir de 2008 passa a ser volume anual com três números.

\section{CONSELHO EDITORIAL}

\section{Afonso Albuquerque}

Universidade Federal Fluminense, Brasil

Alberto Carlos Augusto Klein

Universidade Estadual de Londrina, Brasi

Alex Fernando Teixeira Primo

Universidade Federal do Rio Grande do Sul, Brasil

\section{Alfredo Vizeu}

Universidade Federal de Pernambuco, Brasil

Ana Carolina Damboriarena Escosteguy

Pontifícia Universidade Católica do Rio Grande do Sul, Bras

Ana Silvia Lopes Davi Médola

Universidade Estadual Paulista, Brasil

André Luiz Martins Lemos

Universidade Federal da Bahia, Brasil

Ângela Freire Prysthon

Universidade Federal de Pernambuco, Brasi

Antônio Fausto Neto

Universidade do Vale do Rio dos Sinos, Brasil

Antonio Carlos Hohlfeldt

Pontifícia Universidade Católica do Rio Grande do Sul, Brasil

Arlindo Ribeiro Machado

Universidade de São Paulo, Brasil

César Geraldo Guimarães

Universidade Federal de Minas Gerais, Brasi

Cristiane Freitas Gutfreind

Pontifícia Universidade Católica do Rio Grande do Sul, Brasil

\section{Denilson Lopes}

Universidade Federal do Rio de Janeiro, Brasil

Eduardo Peñuela Cañizal

Universidade Paulista, Brasi

Erick Felinto de Oliveira

Universidade do Estado do Rio de Janeiro, Brasil

Francisco Menezes Martins

Universidade Tuiuti do Paraná, Brasil

Gelson Santana

Universidade Anhembi/Morumbi, Brasil

Hector Ospina

Universidad de Manizales, Colômbia

leda Tucherman

Universidade Federal do Rio de Janeiro, Brasil

Itania Maria Mota Gomes

Universidade Federal da Bahia, Brasil

Janice Caiafa

Universidade Federal do Rio de Janeiro, Brasil

Jeder Silveira Janotti Junior

Universidade Federal da Bahia, Brasil
John DH Downing

University of Texas at Austin, Estados Unidos

José Luiz Aidar Prado

Pontifícia Universidade Católica de São Paulo, Brasil

José Luiz Warren Jardim Gomes Braga

Universidade do Vale do Rio dos Sinos, Brasil

Juremir Machado da Silva

Pontifícia Universidade Católica do Rio Grande do Sul, Brasil

Lorraine Leu

University of Bristol, Grã-Bretanha

Luiz Claudio Martino

Universidade de Brasília, Brasil

Maria Immacolata Vassallo de Lopes

Universidade de São Paulo, Brasil

Maria Lucia Santaella

Pontifícia Universidade Católica de São Paulo, Brasil

Mauro Pereira Porto

Tulane University, Estados Unidos

Muniz Sodre de Araujo Cabral

Universidade Federal do Rio de Janeiro, Brasil

Nilda Aparecida Jacks

Universidade Federal do Rio Grande do Sul, Brasil

Paulo Roberto Gibaldi Vaz

Universidade Federal do Rio de Janeiro, Brasil

Renato Cordeiro Gomes

Pontifícia Universidade Católica do Rio de Janeiro, Brasil

Ronaldo George Helal

Universidade do Estado do Rio de Janeiro, Brasil

Rosana de Lima Soares

Universidade de São Paulo, Brasil

Rossana Reguillo

Instituto Tecnológico y de Estudios Superiores do Occidente, México

Rousiley Celi Moreira Maia

Universidade Federal de Minas Gerais, Brasil

Sebastião Carlos de Morais Squirra

Universidade Metodista de São Paulo, Brasil

Simone Maria Andrade Pereira de Sá

Universidade Federal Fluminense, Brasi

Suzete Venturelli

Universidade de Brasília, Brasil

Valério Cruz Brittos

Universidade do Vale do Rio dos Sinos, Brasi

Veneza Mayora Ronsini

Universidade Federal de Santa Maria, Brasil

Vera Regina Veiga França

Universidade Federal de Minas Gerais, Brasil
COMISSÃO EDITORIAL

Ana Gruszynski I Universidade Federal do Rio Grande do Sul, Brasil João Freire Filho I Universidade Federal do Rio de Janeiro, Brasil Rose Melo Rocha I Escola Superior de Propaganda e Marketing, Brasil

\section{CONSULTORES AD HOC}

Bianca Freire-Medeiros I Fundação Getulio Vargas, Brasil Josimey Costa da Silva I Universidade Federal do Rio Grande do Norte, Brasil Maria Conceiç̃o Golobovante I Pontifícia Universidade Católica de São Paulo, Brasil Marlyvan Moraes de Alencar I Centro Universitário SENAC-SP, Brasil Miriam de Souza Rossini I Universidade Federal do Rio Grande do Sul, Brasil Paulo Ribeiro I Pontifícia Universidade Católica do Rio de Janeiro, Brasil Rita Alves de Oliveira I Centro Universitário SENAC, Brasil

REVISÃO DE TEXTO E TRADUÇÃO I Everton Cardoso

ASSISTÊNCIA EDITORIAL E EDITORAÇ̃̃o ELETRÔNICA I Raquel Castedo
COMPós I www.compos.org.br

Associação Nacional dos Programas de Pós-Graduação em Comunicação

Presidente

Erick Felinto de Oliveira

Universidade do Estado do Rio de Janeiro, Brasil erickfelinto@uol.com.br

Vice-presidente

Ana Silvia Lopes Davi Médola

Universidade Estadual Paulista, Brasil

asilvia@faac.unesp.br

Secretária-Geral

Denize Correa Araújo

Universidade Tuiuti do Paraná, Brasil

denizearaujo@hotmail.com 